DOI 10.18699/SBB-2020-08

\title{
Genetic analysis of some thyme cultivars grown at the Nikita Botanical gardens' collection plots
}

Bulavin I.

FSFIS “The Labour Red Banner Order Nikita Botanical Gardens - National Scientific Center of the RAS”, Yalta, Russia e-mail: labgennbs@yandex.ru

Key words: thyme cultivars, RAPD-PCR, genetic similarity

Motivation and Aim: Breeding of essential oil plants includes demonstration of the distinctive morphological and biochemical characteristics compared to parental forms. In the Nikita Botanical Gardens gene pool collection of the thyme plants are represented by different species, cultivars, forms and chemotypes. The objective of our study was to evaluate the genetic similarity of the thyme cultivars obtained in the NBG.

Methods and Algorithms: Thymus mastichina cv. 'Svetliachok', Thymus striatus cv. 'Jubileiniy' and Thymus vulgaris cv. 'Fantazia' were used. DNAs were isolated from intact young leaves by CTAB-method with $2 \%$ polyvinylpyrolidone (PVP). RAPD-PCR was performed with BioMaster HS-Taq PCR kit (BiolabMix, Russian Federation) and OPA1-6 primers in the C1000 ${ }^{\mathrm{TM}}$ Thermal Cycler (Bio-Rad, Singapore) under the following condition: initial denaturation at $95^{\circ} \mathrm{C}$ for $5 \mathrm{~min}$ followed by 30 cycles of incubation at $94^{\circ} \mathrm{C}$ for $30 \mathrm{~s}$, annealing at $32^{\circ} \mathrm{C}$ for $30 \mathrm{~s}$ and incubation at $72^{\circ} \mathrm{C}$ for $30 \mathrm{~s}$ and with a final extension step at $72{ }^{\circ} \mathrm{C}$ for $5 \mathrm{~min}$. The amplified fragments were analyzed by electrophoresis in $1.5 \%$ agarose gel with $1 \times \mathrm{TBE}$ buffer at $100 \mathrm{~V}$ during $1 \mathrm{~h}$ using universal power supply PowerPacTM (Bio-Rad, Singapore) and imaged with E-box documentation system (Vilber Lourmat, France). DNA polymorphisms generated RAPD-PCR were calculated based on binary matrix in PAST software using Jaccard's similarity coefficient.

Results: Used 6 RAPD primers generated 81 amplicons, ranging basically from $200 \mathrm{bp}$ to $1,500 \mathrm{bp}$ in size. The number of bands in the selected primers varied from 3 (OPA 5) to 7 (OPA 1, 3,6). According to our data, T. mastichina cv. 'Svetliachok' formed separated cluster. Its genetic similarity with T. striatus cv. 'Jubileiniy' was 0.72 and with T. vulgaris cv. 'Fantazia' - 0.78. Similarity between T. striatus cv. 'Jubileiniy' and T. vulgaris cv. 'Fantazia' was 0.86 . Obtained results were natural, since investigated plants, especially T. mastichina, have distinctive morphology and belong to different sections (Mastichina, Thymus and Hyphodromi) according to the botanical classification.

Conclusion: Genetic analysis confirmed that cultivars obtained in the NBG belonged to one group, however were also differed. These differences clearly visible for T. mastichina, T. striatus cv. 'Jubileiniy' and T. vulgaris cv. 'Fantazia' have higher genetic similarity.

Acknowledgements: Supported by State Assignment No. 0829-2019-0038 of the FSFIS "NBG-NSC" and done on the base of the Unique Scientific Installation "Scientific Center of Plant Biotechnology, Genomics and Conservation" of the FSFIS "NBG-NSC". 